\title{
Oligometastatic non-small-cell lung cancer: current treatment strategies
}

\author{
This article was published in the following Dove Press journal: \\ Lung Cancer:Targets and Therapy \\ 4 November 2016 \\ Number of times this article has been viewed
}

\section{Patrick J Richard \\ Ramesh Rengan}

Department of Radiation Oncology, University of Washington, Seattle, WA, USA
Correspondence: Patrick J Richard Department of Radiation Oncology, University of Washington, 1959 NE Pacific Street, Box 356043, Seattle, WA 98195, USA

Email patrick.richard@usoncology.com
Abstract: The oligometastatic disease theory was initially described in 1995 by Hellman and Weichselbaum. Since then, much work has been performed to investigate its existence in many solid tumors. This has led to subclassifications of stage IV cancer, which could redefine our treatment approaches and the therapeutic outcomes for this historically "incurable" entity. With a high incidence of stage IV disease, non-small-cell lung cancer (NSCLC) remains a difficult cancer to treat and cure. Recent work has proven the existence of an oligometastatic state in NSCLC in terms of properly selecting patients who may benefit from aggressive therapy and experience long-term overall survival. This review discusses the current treatment approaches used in oligometastatic NSCLC and provides the evidence and rationale for each approach. The prognostic factors of many trials are discussed, which can be used to properly select patients for aggressive treatment regimens. Future advances in both molecular profiling of NSCLC to find targetable mutations and investigating patient selection may increase the number of patients diagnosed with oligometastatic NSCLC. As this disease entity increases, it is of utmost importance for oncologists treating NSCLC to be aware of the current treatment strategies that exist and the potential advantages/disadvantages of each.

Keywords: oligometastatic, non-small-cell lung cancer, oligoprogressive, treatment

\section{Introduction}

Lung cancer represents the second most common malignancy in both men and women, which is projected to comprise $\sim 115,610$ and 105,590 cases, respectively, in the US in 2015. Unfortunately, lung cancer is the most lethal with an anticipated 158,040 deaths of men and women in 2015. ${ }^{1}$ The most common form of lung cancer is non-smallcell, representing $>80 \%$ of new lung cancer cases in $2014 .^{2}$ A total of $40 \%-50 \%$ of patients with non-small-cell lung cancer (NSCLC) present with stage IV disease. The median survival is $8-11$ months with palliative chemotherapy, consisting of a cisplatin or carboplatin doublet plus a third-generation agent. ${ }^{3}$ Given the poor prognosis, disseminated NSCLC has classically been considered incurable.

A new theory for cancer progression was described by Hellman and Weichselbaum in 1995 , as they put forward the oligometastatic hypothesis. ${ }^{4}$ Their theory was based on a multistep progression of certain types of cancer, such as prostate, colorectal, and melanoma. This theory is supported by molecular evidence that cancer cells can biologically acquire the ability to invade and metastasize sequentially, suggesting different subcategories of metastatic disease..$^{5}$ Early in the metastatic process, there could be limited progression of disease, the so-called oligometastases. If treated aggressively, 
long-term disease control may be possible. The oligometastatic theory is supported in diseases such as colorectal cancer, where even with isolated disease progression to the liver, long-term survival can be achieved when both the primary tumor and liver disease are treated. ${ }^{6,7}$

One organ of particular interest is the lung. Receiving $100 \%$ of cardiac output, the lung is a common site of dissemination for many solid tumors. ${ }^{8-11}$ Therefore, if aggressive management of oligometastatic progression to the lung can achieve long-term disease control in even a small subset of patients, this is potentially impactful. The International Registry of Lung Metastases study examined clinical outcomes in patients undergoing lung metastasectomy for a variety of primary tumor histologies. The 5-year survival was $36 \%$ for all patients and $43 \%$ for patients treated with a solitary lung metastasis. ${ }^{12}$ In recent years, the oligometastatic theory and supporting treatment paradigm have been applied to the management of oligometastatic NSCLC. There has been mostly single institution, retrospective series describing this disease entity and relatively few prospective trials investigating the optimal treatment approach. In this review, we describe the current treatment options for oligometastatic NSCLC and the rationale and evidence to support each approach.

\section{Evidence for existence of an oligometastatic state in NSCLC}

Inherent in the NSCLC oligometastatic theory is the notion that patients can truly be cured and have long-term survival after aggressive treatment of both the primary lung tumor and all metastatic sites. Furthermore, as our understanding of oligometastatic disease advances, there should be reliable and predictable prognostic factors to aid in proper patient selection for this approach. Since early evidence consists of small, retrospective studies, relatively weak conclusions were made regarding which patients benefitted most and which treatment regimens were most effective. A few systematic literature reviews and individual patient meta-analyses were conducted to overcome these limitations.

Ashworth et $\mathrm{al}^{13}$ conducted a systematic review of the oligometastatic NSCLC literature, including 49 publications and 2,176 individual patients with NSCLC with five or fewer metastases. All studies were observational and included patients receiving locally ablative treatment to all sites of oligometastases. Locally ablative treatments consisted of surgical metastasectomy (55\%), stereotactic radiosurgery (SRS; $35 \%$ ), and stereotactic ablative body radiotherapy (RT; 10\%). Outcomes were variable with a median overall survival (OS) of 6.2-52 months (overall median: 19 months) and 5-year
OS results of $8.3 \%-86 \%$ (overall median: $42 \%$ ). Significant predictors for OS included control of the primary tumor, $\mathrm{N}$-stage, and disease-free interval of $>6-12$ months. Since most of the patients were younger with good performance status and a controlled primary tumor, patient selection is of utmost importance.

Another individual patient data meta-analysis better characterized the outcomes and prognostic factors of oligometastatic NSCLC. ${ }^{14}$ A total of 757 patients with one to five synchronous or metachronous metastases (mets), controlled primary tumors, and receiving locally ablative therapy to all metastatic sites were included. The median age was 61.1 years, and $98.3 \%$ of patients had a good performance status. Median OS was 26 months, 5-year OS 29.4\%, and 8-year OS 23.4\%. Median progression-free survival (PFS) was 11 months and 5-year PFS of 13.1\%. Significant factors for OS were metachronous vs synchronous mets, lower N-stage, and histology (adenocarcinoma vs squamous cell). A recursive partitioning model for OS was created based on N-stage and metachronous/synchronous mets, separating patients into low, intermediate, and high risk. Low-risk patients (metachronous mets, any N-stage) seemed to benefit most from aggressive oligometastatic treatment, with 5-year OS of $47.8 \%$, compared to intermediate risk $(36.2 \%)$ and high risk (13.8\%). Given the relatively high 5-year OS of the overall and low risk, this study supports the oligometastatic NSCLC entity.

Although debate remains regarding the existence of an oligometastatic state, these studies highlight that certain patients may benefit from aggressive treatment of all sites of disease and may indeed be considered to have oligometastatic NSCLC. Importantly, patient selection is a key determinant in deciding optimal treatment approaches.

\section{Overview of treatment options and algorithm}

As was highlighted in the aforementioned studies, there are many potential treatment options for oligometastatic NSCLC, ranging from upfront systemic therapy \pm local treatments to avoiding systemic therapy and treating all sites of disease with aggressive local treatments. Given the lack of a randomized controlled trial, there are many viable options. To better organize the discussion of the various treatment options and supporting literature, we have created a treatment algorithm, based upon our institutional approach (Figure 1).

Conceptually and prognostically, one of the most important distinctions in oligometastatic NSCLC is between the synchronous vs metachronous presentation of metastases. 


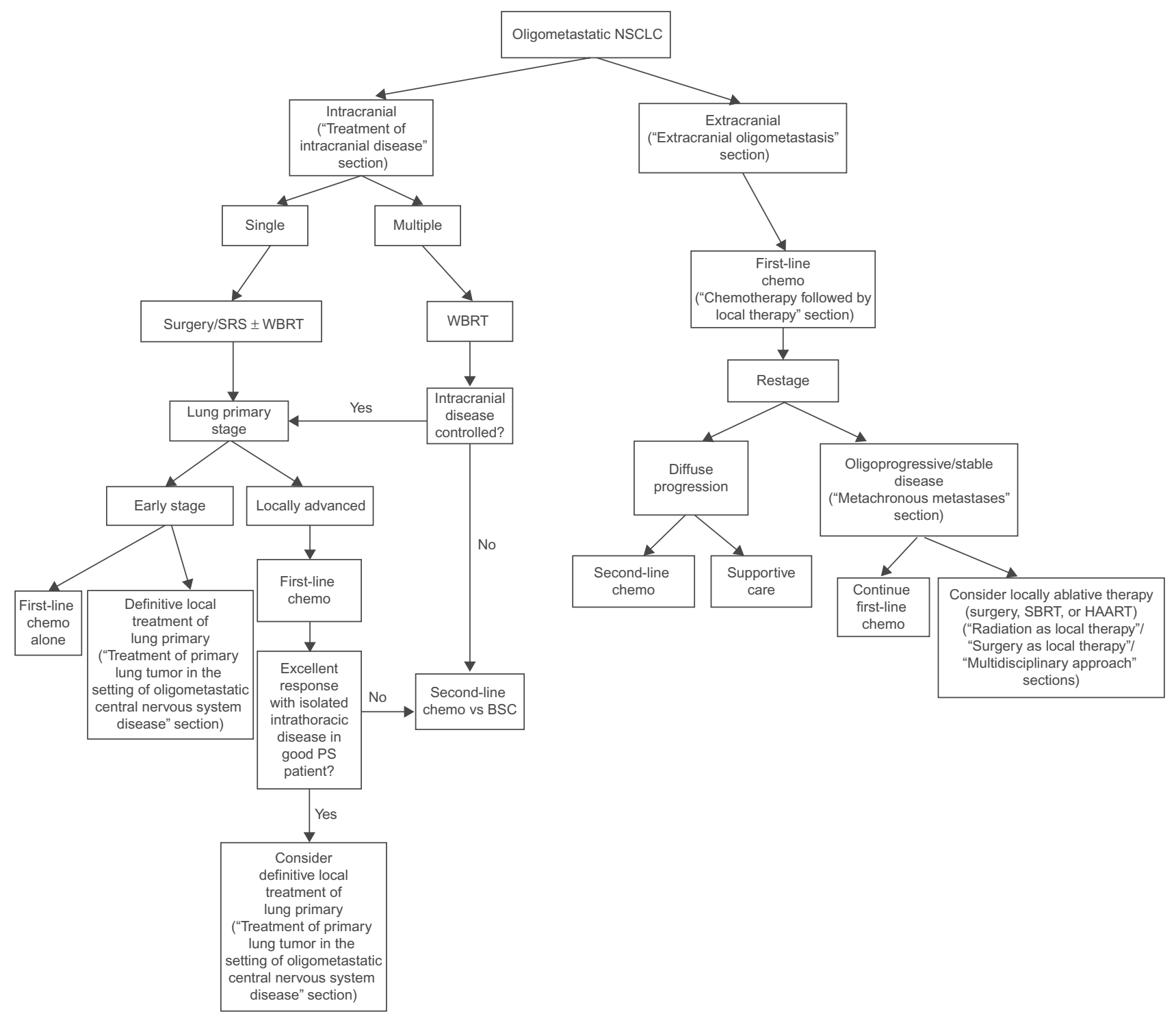

Figure I Treatment algorithm demonstrating different clinical scenarios of oligometastatic NSCLC and possible treatment paradigms.

Note: When applicable, numbers in parentheses refer to section of manuscript where each treatment option is discussed.

Abbreviations: NSCLC, non-small-cell lung cancer; SRS, stereotactic radiosurgery; WBRT, whole brain radiotherapy; chemo, chemotherapy; PS, performance status; HAART, highly active anti-retroviral therapy; BSC, best supportive care; SBRT, stereotactic body radiation therapy.

Synchronous metastasis is present at the time of initial diagnosis of NSCLC, whereas metachronous mets develop after initial therapy. Metachronous can further include mets that develop after an initial disease-free interval or oligoprogressive disease that persists or grows after initial systemic therapy. It has been previously demonstrated that metachronous oligometastases (oligomets) carry a more favorable prognosis compared to synchronous. ${ }^{14,15}$

Another important distinction is whether the oligometastases are intra- or extracranial in location. Given the poor penetrance of traditional systemic therapy across the blood-brain barrier, intracranial-only metastases may not be adequately controlled, leading to significant neurologic mortality and morbidity. Priority is usually given to the local treatment of the intracranial disease first, followed by the primary and other extracranial oligometastases.

\section{Synchronous oligometastases Intracranial only} Treatment of intracranial disease

Approximately $30 \%-50 \%$ of patients with NSCLC will develop brain metastases, and $\sim 10 \%$ will have brain mets at initial diagnosis. ${ }^{16}$ Brain metastases can lead to neurologic morbidity and mortality from progressive disease and/or effects of local treatment. However, the Radiation Therapy Oncology Group conducted a recursive partitioning analysis of brain metastatic patients with several histologies to determine risk classes. ${ }^{17}$ These recursive partitioning analysis 
classes are helpful in determining the most appropriate treatment of the intracranial component of disease.

In general, three main treatment options exist: surgical excision, RT (whole brain, SRS, both), or a combination of surgery and RT. Historically, in patients with a limited number of brain mets amenable to resection, surgical excision was considered the best initial treatment. Landmark studies by Patchell et al established improvements in local control (20\% vs 52\%) and OS (median 40 weeks vs 15 weeks) with the addition of surgery prior to whole brain radiation and improved local control (10\% vs 46\%), distant intracranial control (14\% vs $37 \%$ ), and neurologic death (14\% vs $44 \%$ ) with the addition of adjuvant whole brain radiation to surgery for solitary brain mets. ${ }^{18,19}$

Depending on the surgical candidacy of the patient, craniotomy may not be feasible. In recent years, advancements in the localization, planning, and delivery of RT have allowed for the extremely precise and accurate intracranial radiation technique called SRS. Being minimally invasive, SRS seems to have equivalent outcomes and safety compared to surgery. ${ }^{20}$ In particular, several studies have used SRS instead of surgical excision in combination with whole brain RT (WBRT) when multiple (2-4) brain mets are present. ${ }^{21-24}$ Local control rates are $\sim 50 \%-92 \%$ with combined whole brain radiation and SRS. Without randomized evidence comparing surgery to SRS, there is inconclusive evidence regarding which is superior. Treatment decisions are determined by the overall health/performance status, location/number/size of each lesion, and presence of symptoms. Consideration should be given to the future treatment of the primary lung tumor/other sites of metastases, as choice of intracranial treatment may limit/impact the ability to tolerate further therapy.

Although chemotherapy is the historical treatment for stage IV NSCLC, there are concerns over the ability of chemotherapy agents (platinums and taxanes) to cross the blood-brain barrier, which possibly explains the inferior response rates of $20 \%-40 \% .{ }^{25,26}$ However, current work with small molecule inhibitors, such as gefitinib and erlotinib, could reveal that these agents may be able to cross the bloodbrain barrier and control intracranial disease.

\section{Treatment of primary lung tumor in the setting of oligometastatic central nervous system disease}

It should be noted that chemotherapy is an appropriate standard of care for these patients. However, in certain select subsets of patients, surgery and radiation \pm chemotherapy are the two potential options for aggressive control of and treating the primary lung tumor after addressing the intracranial disease. The supporting literature is composed of small to moderately large retrospective studies. Surgery alone is considered a viable option when obtaining a complete resection (presumably with earlier stage primary lung tumors), with the possibility of using adjuvant radiation if incomplete resection is obtained. For larger primary tumors or advanced nodal disease (N2-3), RT (with or without chemotherapy) is likely more beneficial.

\section{Surgery for primary lung cancer}

The largest of all the surgical series was conducted by Wroński et al, consisting of a retrospective review of 231 patients with NSCLC who underwent resection of brain mets from 1976 to $1991 .{ }^{27}$ Approximately $33 \%$ of patients also had systemic mets, most of which were diagnosed after craniotomy. The median age of the cohort was 56 years, and $\sim 80 \%$ of these patients had surgical resection of the primary lung cancer. The remainder of the patients underwent chemotherapy and/ or radiation for primary tumors deemed unresectable. In addition, $84 \%$ of patients received WBRT (median dose: $30 \mathrm{~Gy}$ ) either before or after craniotomy (66.2\% after craniotomy). The primary lung tumor recurred in $\sim 41.6 \%$ of these patients (median time: 299 days). There was a significant correlation between the degree of resection and survival, with a median survival of 14.4 months in patients with complete resection and 6.6 months in patients who were incompletely resected/ unresectable. On multivariate analysis, five factors were considered to significantly impact survival: extent of primary lung tumor resection, location of lesion, sex, presence of systemic metastases, and age above/below 60 years.

Another study by Bonnette et al included 103 patients with NSCLC with synchronous brain mets (96\% with a solitary brain metastasis), who underwent surgical resection of the primary lung tumor with or without perioperative chemotherapy ( $40 \%$ of patients). ${ }^{28}$ The majority of patients (91\%) underwent craniotomy prior to lung tumor surgery. Seventy-three percent of patients received adjuvant whole brain radiation alone, resection cavity radiation alone, or WBRT with cavity boost (doses ranged from 20 to $50 \mathrm{~Gy}$ ). Thoracic surgery consisted of lobectomies (67\%), pneumonectomies (24\%), segmentectomies ( $2 \%)$, and wedge resection (7\%). Approximately $32 \%$ of patients received adjuvant RT to the thorax, which was indicated given node-positive disease at surgery. RT doses ranged from 45 to $55 \mathrm{~Gy}$. The OS at 1 year, 2 years, 3 years, and 5 years was $56 \%, 28 \%, 13 \%$, and $11 \%$, respectively. The median survival was 12.4 months. Fourteen percent of patients developed thoracic recurrence and $41 \%$ had brain tumor recurrences with or without other 
systemic recurrences. Forty-two percent of the brain recurrences have occurred in patients who did not receive brain RT. Only histology seemed to significantly impact OS time (adenocarcinoma better than epidermoid/large cell).

Other retrospective series demonstrated the prognostic significance on survival for patients undergoing complete thoracic tumor resection (median survival: 16-26 months), negative lymph nodes (median survival: 18 months), or stages I-II primary lung lesions (median survival: 18 months). ${ }^{29-31}$

\section{Radiation for primary lung cancer}

Radiation alone or in combination with chemotherapy is a reasonable treatment option, particularly for patients with locally advanced primary NSCLC tumors. Extrapolating from the nonmetastatic locally advanced NSCLC data, surgery does not improve OS or PFS compared to radiation with chemotherapy. ${ }^{32,33}$

One of the largest retrospective series was conducted by $\mathrm{Hu}$ et al and included 84 patients with solitary brain-only oligometastatic NSCLC who received radiation \pm chemotherapy for primary lung tumor management (median RT dose: 45 Gy). ${ }^{34}$ The lung tumors were staged as I in $14 \%$, II in $32 \%$, and III in 54\%. Approximately $52 \%$ of patients also received treatment to the primary lung tumor. Of these, $18 \%$ of patients received radiation alone, $52 \%$ received chemotherapy alone, and 30\% received chemotherapy-RT. There was improved OS for patients receiving primary tumor treatment (median 15.5 vs 5.9 months). The 2 -year primary tumor recurrence-free survival was $53 \%$ for stage I primaries and $24 \%$ for nonstage I primaries. The investigators concluded that aggressive treatment of the primary tumor and solitary brain metastasis was certainly indicated for stage I thoracic primaries, given the better-than-expected survival in that cohort.

In a contemporary series by Arrieta et al, ${ }^{35}$ the outcomes of 30 patients with primary NSCLC tumor and synchronous brain-only metastases were reported. The treatment approach consisted of WBRT only for intracranial control and systemic therapy with cisplatin/paclitaxel for two cycles. Response was then assessed at both the primary and intracranial tumor location after the first two cycles of chemotherapy. If all sites of disease were controlled, definitive chemoradiation was delivered. Concurrent chemoradiation consisted of thoracic radiation to a median dose of 60 Gy concurrent with carboplatin and paclitaxel. An additional four cycles of cisplatin/paclitaxel was given after chemoradiation if there was no evidence of progression. Thoracic primary tumors were stable in $40 \%$ of patients and demonstrated a partial response in 60\%. Median OS and PFS were 32 and 8.5 months, respectively. PFS was $40 \%$ at 1 year and $25 \%$ at 2 years. Furthermore, 3-year OS was superior in patients with N0-1 disease (60\%) compared to N2-3 disease (24\%). The median OS reported was one of the longest compared to other retrospective reviews. Potential explanations were the young median age, good performance status, and use of induction chemotherapy prior to definitive chemoradiation. These results highlight the importance of patient selection and the potential benefit of induction chemotherapy as a mechanism to select for patients with more indolent micrometastatic disease.

In summary, the brain-only oligometastatic patients with NSCLC who seem to benefit most from both aggressive local and intracranial management are highly selected patients with younger age, good performance status, and limited stage lung primaries. Although there is inconclusive evidence regarding the best primary and intracranial treatments, we have highlighted several treatment regimens that have produced long-term survival in this historically unfavorable disease entity. Aside from the studies discussed earlier, Table 1 highlights the selected studies using either surgery or radiation for local treatment of the primary lung cancer in patients with brain-only mets.

\section{Extracranial oligometastasis Chemotherapy followed by local therapy}

Since the historical treatment for stage IV NSCLC was systemic therapy, a common treatment strategy for oligometastatic NSCLC is upfront systemic therapy. After initiation of systemic therapy, patients with synchronous oligomets may be candidates for "definitive/consolidative" ablative treatment to remaining sites. The rationale is that previous studies have demonstrated that select patients with stage IV NSCLC will progress only at local sites of previous metastasis. Rusthoven et $\mathrm{al}^{36}$ demonstrated that local-only metastatic progression occurred in $68 \%$ of patients after first-line systemic therapy, suggesting a role for consolidative/definitive management of those distant sites. Mehta et $\mathrm{al}^{37}$ published an analysis of patients treated on a Phase II protocol of oxaliplatin/paclitaxel. Sixty-five percent of their study population of patients with $\leq 4$ metastases had stable or progressive disease at initially involved sites only. These two studies provide rationale for the use of locally aggressive treatments for oligomets following systemic therapy.

There is also evidence highlighting the importance of control of the primary lung tumor in the setting of limited extrathoracic disease. Xanthopoulos et $\mathrm{al}^{38}$ conducted a 
Table I Select studies of intracranial-only oligometastases with definitive primary lung treatment

\begin{tabular}{|c|c|c|c|c|c|}
\hline Study & Timing of mets & $\begin{array}{l}\text { Tx primary lung } \\
\text { tumor }\end{array}$ & $\begin{array}{l}\text { Tx intracranial } \\
\text { disease }\end{array}$ & Outcomes & Prognosis (favorable) \\
\hline Mozami et al $\left.\right|^{58}$ & Metachronous only & $\begin{array}{l}\text { Chemo + RT } \\
\text { Chemo + surgery } \\
\text { Trimodality } \\
\text { Surgery alone }\end{array}$ & $\begin{array}{l}\text { WBRT alone } \\
\text { SRS } \pm \text { WBRT } \\
\text { Surgery } \pm \text { WBRT }\end{array}$ & $\begin{array}{l}\text { I-y OS: } 22 \% \\
2-y \text { OS: } 10 \%\end{array}$ & $\begin{array}{l}\text { Young age } \\
\text { Good KPS } \\
\text { Stage IIIA primary tumor } \\
\text { Lung resection } \\
\text { No extracranial mets } \\
\text { Either metastasectomy/SRS for mets }\end{array}$ \\
\hline Abrahams et $\mathrm{al}^{59}$ & $\begin{array}{l}\text { Both synchronous } \\
\text { and metachronous }\end{array}$ & $\begin{array}{l}\mathrm{CT}+\mathrm{RT} \\
\text { Thoracotomy } \pm \\
\text { chemo-RT }\end{array}$ & $\begin{array}{l}\text { Surgery } \pm \text { WBRT or } \\
\text { SRS } \\
\text { WBRT or SRS } \\
\text { supportive care only }\end{array}$ & $\begin{array}{l}\text { I-y OS: } 52 \% \\
2-y \text { OS: } 31 \% \\
3-y \text { OS: } 13 \% \\
5-y \text { OS: } 11 \%\end{array}$ & $\begin{array}{l}\text { Performance status (KPS I00 vs } \leq 90 \text { ) } \\
\text { Metachronous presentation }\end{array}$ \\
\hline Flannery et $\mathrm{al}^{60}$ & $\begin{array}{l}\text { Synchronous solitary } \\
\text { mets only }\end{array}$ & $\begin{array}{l}\text { Surgery only } \\
\text { Chemo + RT } \\
\text { Surgery + } \\
\text { chemo + RT } \\
\text { (also included } \\
\text { nondefinitive } \\
\text { treatments) }\end{array}$ & $\begin{array}{l}\text { Gamma knife SRS + } \\
\text { WBRT } \\
\text { SRS alone }\end{array}$ & $\begin{array}{l}\text { OS I8 months: } \\
\text { I-y OS: } 71 \% \\
2-y \text { OS: } 34 \% \\
5-y \text { OS: } 21 \%\end{array}$ & $\begin{array}{l}\text { KPS } \\
\text { Primary lung treatment with surgery }\end{array}$ \\
\hline
\end{tabular}

Abbreviations: Chemo, chemotherapy; CT, computed tomography; OS, overall survival; RT, radiotherapy; SRS, stereotactic radiosurgery; WBRT, whole brain RT; y, year; tx, treatment; mets, metastases; KPS, Karnofsky performance status.

retrospective review of oligometastatic stage IV patients with NSCLC ( $\leq 4$ sites of metastases), who received at least 50 Gy of thoracic radiation to the primary tumors. The median survival was 22 months in those patients compared to 9 months in patients receiving chemotherapy alone. Treating the primary tumor aggressively also prolonged median time to local failure (18 vs 6 months)

The use of upfront chemotherapy may allow for optimal patient selection of those who will not have rapid systemic progression on first-line chemotherapy. Although there are no randomized controlled trials of this approach, there are a few prospective Phase II trials using various systemic therapy backbones and local treatments. Selected studies are discussed in the following sections.

\section{Radiation as local therapy}

Stereotactic body radiation therapy (SBRT) involves the accurate and precise delivery of ablative doses of radiation in a limited number of fractions. SBRT is effective in early-stage NSCLC, particularly in the medically inoperable patients. ${ }^{39}$ There is growing evidence using SBRT for various malignancies with limited metastatic disease burden, producing 2-year local control rates exceeding $90 \%{ }^{40-42}$

A Phase II multi-institutional trial by Iyengar et al included patients with $\leq 6$ sites of oligometastases (excluding intracranial mets), who had progressed through prior chemotherapy regimens. ${ }^{43}$ The intervention investigated was SBRT with erlotinib, and all metastatic sites had to be amenable for SBRT. Erlotinib was given 1 week prior to SBRT and continued during/after the SBRT course until disease progression. SBRT regimens ranging from one to five fractions were allowed. A total of 24 patients were enrolled between 1997 and 2014. Median age of the population was 67 years, and median follow-up was 16.8 months. The majority of the extracranial sites treated were lungs (35\%), mediastinum/hilum (25\%), and adrenals (13\%). SBRT was used to treat all sites of mets, and the average duration of erlotinib treatment was 273 days. Median PFS and OS was 14.7 months and 20.4 months, respectively. The 6-month PFS rate (primary end point) was $69 \%$, including $6 \%$ local-only failures. Univariate analysis demonstrated that the number of SBRT-treated sites was associated with higher death and progression rate (hazard ratio $=1.512$ ). SBRT possibly caused one grade 5 toxicity (acute respiratory distress syndrome/pneumonia 3 months after SBRT). Otherwise, SBRT could have contributed to one grade 4 and two grade 3 toxicities. The investigators concluded that this regimen was safe and led to encouraging PFS and OS.

Another Phase II study from investigators in Belgium used SBRT (50 Gy in five fractions) for patients with oligometastatic ( $\leq 5$ sites) NSCLC after induction chemotherapy or upfront SBRT who were not candidates for systemic therapy because of medical comorbidities, low tumor burden, or patient preference ${ }^{44}$ SBRT was delivered to both the primary tumor sites and all distant metastases. Disease response was assessed with pre- and post-SBRT positron emission tomography/computed tomography scans. The average age in their cohort was 62 years, the majority of the patients presented with synchronous mets ( $73 \%$ ), and $\sim 65 \%$ of patients had received induction chemotherapy. Approximately 50\% of patients had mets to the lungs/mediastinal lymph nodes. 
The median OS and PFS were 23 and 11.2 months, respectively (2-year OS rate: 49\%). OS was significantly better for patients with synchronous mets and induction chemotherapy. Acute grade II and III pulmonary/esophageal toxicities were reported in $15 \%$ and $8 \%$ of patients, respectively. Although this was a small prospective study, it certainly adds evidence regarding the efficacy and safety of SBRT to both the primary tumor and mets in properly selected patients.

The encouraging results of these trials have prompted the current SABR-COMET randomized Phase II trial. ${ }^{45}$ Although this study includes several histologies, it investigates whether SBRT to all sites of mets in patients with controlled primaries improves OS and quality of life compared to standard of care (palliative-intent radiation). The experimental arm consists of either "traditional" SBRT in one to five fractions or hypofractionated radiation courses of six to eight fractions. Depending on the results, a Phase III trial may then be warranted. Table 2 describes selected studies using either SBRT or hypofractionated radiation for local therapy.

\section{Surgery as local therapy}

Surgical management of extracranial oligometastatic NSCLC is limited to patients who are deemed medically operable with anatomically resectable primary tumors, usually with a solitary met only. There should be more consideration given to the sequencing of surgery with systemic therapy, as one modality could significantly affect the ability of the patient to tolerate the other.
Beginning with a backbone of systemic therapy can potentially select for patients who may not develop overt systemic disease and would most benefit from aggressive local therapy. However, upfront surgery may allow for optimal debulking/cytoreduction and improve performance status heading into chemotherapy.

Because surgery predates SBRT, many of the initial treatment paradigms for solitary oligometastases included surgical excision. Previous retrospective studies and case reports showed excellent disease control, low rates of toxicity, and modestly improved OS with resection of solitary mets. ${ }^{46-48}$

In 2002, researchers at Memorial Sloan Kettering Cancer Center published a Phase II trial of induction chemotherapy followed by surgical resection of both the primary lung tumor and solitary site of oligometastasis. ${ }^{49}$ Eligible patients were those with potentially resectable intrathoracic disease (T1-3, N0-2) and underwent initial induction chemotherapy with IV mitomycin $\mathrm{C}\left(8 \mathrm{mg} / \mathrm{m}^{2}\right.$ on days 1 , 29 , and 71$)$, vinblastine $\left(4.0 \mathrm{mg} / \mathrm{m}^{2}\right.$ on days $1,15,22$, and $29 ; 2.0 \mathrm{mg} / \mathrm{m}^{2}$ on day 8 only), and cisplatin $\left(120 \mathrm{mg} / \mathrm{m}^{2}\right.$ on days 1, 29, and 71). After induction chemotherapy, patients were restaged, and if amenable, proceeded to resection of all sites of disease. Lung resection was lobectomy or pneumonectomy and mediastinal lymph node dissection. Postoperatively, patients received two cycles of vinblastine and cisplatin. The majority of patients had prior brain mets only (14/23) and received resection of the brain mets, followed by chemotherapy, followed by thoracic resection.

Table 2 Select studies using radiation \pm surgery for aggressive treatment of both primary tumor and mets

\begin{tabular}{|c|c|c|c|c|}
\hline Study & RT technique/dose & Treatment details & Outcomes & Prognosis \\
\hline Parikh et $a^{61}$ & $\begin{array}{l}\text { SBRT or standard } \\
\text { fractionation with } \\
\text { at least BED } \\
10 \geq 53 \text { Gy }\end{array}$ & $\begin{array}{l}\text { Local tx to primary } \\
\text { tumor and mets } \\
\text { No treatment for primary } \\
\text { tumor or mets } \\
\text { Primary treatment only } \\
\text { Mets treatment only }\end{array}$ & $\begin{array}{l}\text { Median OS: } 17 \text { months } \\
\text { (19 months if primary } \\
\text { tumor is treated vs } \\
16 \text { months if not) }\end{array}$ & $\begin{array}{l}\text { Unfavorable (MVA): } \\
\text { ECOG PS } \geq 2 \\
\text { Nodal status (N2-N3) } \\
\text { SCC path } \\
\text { Multiple organ mets } \\
\text { Favorable: } \\
\text { Definitive local therapy to } \\
\text { primary tumor }\end{array}$ \\
\hline Lopez Guerra et al ${ }^{62}$ & $\begin{array}{l}\text { Required biologically } \\
\text { equivalent dose } \\
\text { of } 60 \mathrm{~Gy} \text { in } 2 \mathrm{~Gy} \\
\text { fractions }\end{array}$ & $\begin{array}{l}\text { All patients received definitive } \\
\text { chemo-RT to the primary } \\
\text { tumor. Primary tumor } \\
\text { treatment only ( } 44 \%) ; \\
\text { primary tumor and met } \\
\text { treatment (56\%) }\end{array}$ & $\begin{array}{l}1-y \text { OS: } 62 \% \\
2-y \text { OS: } 32 \% \\
3-y \text { OS: } 25 \%\end{array}$ & $\begin{array}{l}\text { Favorable (MVA) } \\
\text { Radiation dose }>63 \mathrm{~Gy} \\
\text { Higher performance status } \\
\text { Smaller tumor volume }\end{array}$ \\
\hline Hasselle et $a^{63}$ & $\begin{array}{l}\text { Hypofractionated } \\
\text { image-guided RT }\end{array}$ & $\begin{array}{l}\text { Most patients received } \\
\text { chemo or targeted agents } \\
\text { prior to radiation; radiation } \\
\text { to all sites of disease } \\
\text { Treatment to residual after } \\
\text { chemo }(28 \%)\end{array}$ & $\begin{array}{l}\text { Local control at } 12 \text { months: } 75 \% \\
\text { and I8 months: } 66 \% \\
\text { Median OS: } 22.7 \text { months } \\
\text { Median PFS: } 7.6 \text { months } \\
\text { I2-month OS: } 81 \% \\
\text { I8-month OS: } 53 \%\end{array}$ & $\begin{array}{l}\text { Patients with local control } \\
\text { after treatment with RT } \\
\text { had improved I2-month } \\
\text { and I8-month OS } \\
\text { compared to those with } \\
\text { local failure }\end{array}$ \\
\hline
\end{tabular}

Abbreviations: Chemo, chemotherapy; OS, overall survival; PFS, progression-free survival; RT, radiotherapy; SBRT, stereotactic body radiation therapy; SCC, squamous cell carcinoma; y, year; tx, treatment; mets, metastases; MVA, multivariate analysis; ECOG, Eastern Cooperative Oncology Group; PS, performance status; BED, biologically equivalent dose. 
Only 12 patients were able to undergo all three cycles of induction chemotherapy. After induction chemotherapy, nine patients had no response, three had minor response, eight had partial response, and zero had complete response. Of the patients who underwent surgical excision, an R0 resection was accomplished in $93 \%$ of cases and $60 \%$ of these patients proceeded to adjuvant chemotherapy. The median OS for all patients was 11 months. Results suggest that the sequence of treatment using induction chemotherapy followed by surgery may not be feasible since many patients were unable to complete all cycles. Furthermore, OS was lower than previous reports, and the authors could not conclude that the approach of chemotherapy and surgery was tolerable or effective. Table 3 highlights the other select studies of surgical resection of both the primary tumor and oligomets.

\section{Multidisciplinary approach}

Given the importance in patient selection and the difference in morbidity between the treatment paradigms, oligometastatic patients should be discussed in a multidisciplinary setting. Although the studies discussed earlier used either surgery or radiation as the modality of choice, it could be that some patients would benefit from a combination of both.

De Ruysscher et al conducted a prospective Phase II trial of patients with oligometastatic ( $\leq 5$ mets) NSCLC amenable to radical local treatment with either surgery or radiation \pm chemotherapy to primary tumor and all distant sites..$^{50}$ Locoregional treatment to the primary tumor consisted of lobectomy and node dissection, SBRT, or more fractionated courses (centrally located lung tumors). Advanced lung primaries were treated with sequential or concurrent chemotherapy-RT. Treatment of the distant mets ranged from surgical resection

Table 3 Select studies using surgery \pm radiation/chemo for aggressive treatment of both primary tumor and mets

\begin{tabular}{|c|c|c|c|c|}
\hline Study & $\begin{array}{l}\text { Surgical technique for } \\
\text { primary tumor }\end{array}$ & Treatment of oligomets & Outcomes & Prognosis \\
\hline Collaud et al ${ }^{64}$ & $\begin{array}{l}\text { Pneumonectomy } \\
\text { Bilobar resection } \\
\text { Lobar resection; sublobar } \\
\text { resection } \\
\text { (I7\% rate of RI resection) }\end{array}$ & $\begin{array}{l}\text { Pulmonary mets treated with } \\
\text { staged thoracotomy } \\
\text { Brain mets treated with surgery } \\
\text { and post-op WBRT } \\
\text { Adrenal mets treated with lap } \\
\text { adrenalectomy }\end{array}$ & $\begin{array}{l}\text { Median OS: } 20.5 \text { months } \\
\text { I-y OS: } 65 \% \\
\text { 5-y OS: } 36 \%\end{array}$ & $\begin{array}{l}\text { Favorable (UVA): lower } \\
\text { pathologic T-stage }\end{array}$ \\
\hline $\begin{array}{l}\text { Tanvetyanon et al } \\
: \text { pooled analysis }\end{array}$ & Pneumonectomy & $\begin{array}{l}\text { Either: } \\
\text { Laparoscopic adrenalectomy } \\
\text { Chemotherapy } \\
\text { XRT to adrenal bed }\end{array}$ & $\begin{array}{l}\text { Median OS: synchronous } \\
\text { (I2 months); metachronous } \\
\text { (3I months) } \\
\text { I-y OS/2-y OS: synchronous } \\
\text { (45\%/30\%); metachronous } \\
\text { (80\%/52\%) } \\
\text { Median DFS: synchronous } \\
\text { ( } 9 \text { months); metachronous } \\
\text { (II months) }\end{array}$ & UVA or MVA not stated \\
\hline Voltolini et al ${ }^{65}$ & $\begin{array}{l}\text { Unilateral tumors mainly } \\
\text { got lobectomy/sublobar or } \\
\text { pneumonectomy } \\
\text { Bilateral tumors mainly got } \\
\text { lobectomy/sublobar resectior } \\
\text { and bilateral lobectomy }\end{array}$ & $\begin{array}{l}\text { Adjuvant treatment: mostly } \\
\text { chemo alone }\end{array}$ & $\begin{array}{l}\text { Median OS (pts getting } \\
\text { resection): } 32 \text { months } \\
3-y / 5-y \text { OS: } 41 \% / 34 \%\end{array}$ & $\begin{array}{l}\text { Unfavorable (MVA): } \\
\text { Lymph node positive } \\
\text { Surgery before year } \\
2000\end{array}$ \\
\hline Hanagiri et $\mathrm{al}^{66}$ & Mostly lobectomy & $\begin{array}{l}\text { Adjuvant chemo given if tolerated } \\
\text { (carbo/paclitaxel or carbo/gem) } \\
\text { XRT given to bone mets } \\
\text { SRS given to brain mets } \\
\text { Adrenal mets were resected }\end{array}$ & $\begin{array}{l}\text { 5-y OS: } \\
26.8 \% \text { (entire population) } \\
50.3 \% \text { (single met) } \\
16.7 \%(\geq 2)\end{array}$ & UVA or MVA not stated \\
\hline
\end{tabular}

Abbreviations: carbo, carboplatin; chemo, chemotherapy; DFS, disease-free survival; gem, gemcitabine; OS, overall survival; postop, post-operative; pts, points; RT, radiotherapy; SRS, stereotactic radiosurgery; WBRT, whole brain RT; y, year; tx, treatment; mets, metastases; MVA, multivariate analysis; UVA, univariate analysis; XRT, radiation therapy. 
alone if completely resected, radiation alone if not operable, or surgery + radiation if an $\mathrm{R} 1$ resection. The majority of the enrolled 40 patients were locally advanced ( $75 \%)$, and the brain was the most frequent site of distant mets. In all patients, the primary tumor/regional nodes were treated with RT alone (one patient received SBRT) or chemoradiation. Surgery was used for solitary mets in the brain, adrenal glands, ovaries, lungs, or liver. With a median follow-up of 27 months, the median OS and PFS was 13.5 and 12.1 months, respectively. The 3-year rates of OS and PFS were $17.5 \%$ and $13.6 \%$, respectively. Of those who progressed, only $5 \%$ had an in-field recurrence. Fifteen percent of patients did not progress after 2 years. The only grade III toxicities were both physician-reported and patient-reported dysphagia (15.4\% and $23.1 \%$, respectively).

\section{Metachronous metastases}

Patients who develop metachronous oligomets after definitive local therapy for NSCLC (also termed oligoprogressive disease) or after prolonged disease-free intervals (oligorecurrence) have several treatment options: surgery, radiation, or a combination (especially with intracranial mets). Once again, patient selection is critical to determine the optimal approach, given the differences in morbidity and patient preference between the two main modalities.

A retrospective study by Yano et al included 13 patients initially treated with surgery for an early-stage NSCLC, who developed distant-only, extracranial oligometastases ( $\leq 3$ sites). ${ }^{51}$ Of these patients, eleven of them received local treatment to the mets, consisting of surgery alone (three) and RT alone (eight). RT regimens consisted of either SBRT in 2-4 fractions or hypofractionated courses in 15-17 fractions. Median PFS was 20 months for the patients receiving local treatment to the mets, and five patients had PFS longer than 2 years. The study demonstrated that longer PFS can be obtained in the metachronous NSCLC population with aggressive local treatment of the mets.

Given the more favorable prognosis and longer diseasefree intervals in the metachronous oligometastatic setting, one approach is to aggressively treat the distant mets with either surgery or radiation. If/when the tempo or quantity of mets exceeds what can reasonably be controlled with local therapy, systemic therapy is usually warranted.

With recent advances in identifying subsets of patients with NSCLC with targetable mutations (EGFR, ALK), there is potential to increase the disease-free interval and therefore improve OS. Recent evidence has emerged suggesting improved PFS and objective response rates with crizotinib in patients with locally advanced, recurrent, or metastatic ALK-positive non-squamous cell carcinoma NSCLC. ${ }^{52}$ Similarly, patients with NSCLC with activating EGFR mutations have shown benefits in terms of PFS with the use of erlotinib compared to standard chemotherapy (ie, cisplatin-docetaxel, cisplatin-gemcitabine, or single-agent carboplatin or gemcitabine) ${ }^{53}$ As patients with NSCLC with specific mutations experience prolonged PFS with targeted therapy, there may be an increase in the number of metachronous/oligoprogressive patients as tumor cells eventually acquire resistance to those agents. ${ }^{54,55}$ Several small studies have demonstrated the importance of local control in these patient populations.

Gan et al conducted a retrospective review of 38 patients with ALK + NSCLC treated with crizotinib. ${ }^{56}$ Thirty-three of these patients had a first progression either intracranial $(n=13)$, extracranial $(n=18)$, or both $(n=2)$. The median PFS of overall first relapse was 9.1 months on crizotinib (17 months for extracranial progression). Fourteen patients with extracranial disease progression received initial locally ablative therapy, consisting of hypofractionated radiation, SBRT, or surgery. The local control of the patients receiving locally ablative treatment was $100 \%$ and $86 \%$ at 6 and 12 months, respectively. All lesions that were amenable to SBRT were controlled at 6 and 12 months. The median PFS for the 14 patients receiving crizotinib and locally ablative treatments was 14 months, compared to 7.2 months in patients not eligible for local treatment. Eligible patients for local treatments also had longer durations of crizotinib (median 28 months). Importantly, the duration of crizotinib $>12$ months was associated with prolonged OS at 2 years compared to a duration of $<12$ months $(72 \%$ vs $12 \%)$. The conclusions were that patients with ALK + NSCLC developing oligoprogression on crizotinib may be eligible for locally ablative treatments of presumed resistant tumor subclones and, thereby continue on crizotinib that is perceived beneficial in targeting nonmutated subclones.

A similar study was conducted by $\mathrm{Yu}$ et $\mathrm{al}^{57}$ in patients with EGFR + metastatic NSCLC treated with a tyrosine kinase inhibitor. They demonstrated that patients eligible for local treatment to oligoprogressive disease had a median time to progression of 10 months after local treatment and a median OS of 41 months. Importantly, $85 \%$ of patients were able to restart tyrosine kinase inhibitor therapy within 1 month of local treatment, and median time to systemic therapy change was 22 months.

Both these studies highlight the importance of patient selection for locally ablative treatments as well as the 
importance of continuing the targeted therapies for as long as clinically beneficial.

\section{Discussion}

After the original postulation of the oligometastasis hypothesis by Hellman and Weichselbaum in 1995, much work has been performed to prove this theory in a variety of cancer types. This has provided new potential therapeutic algorithms to provide long-term disease control in the metastatic setting. Since the outcomes in stage IV NSCLC historically have been poor (median OS: 8-11 months), the search for evidence of oligometastatic NSCLC has been particularly relevant and meaningful.

Through the work mentioned earlier, there appears to be an oligometastatic disease state in select patients with NSCLC: controlled primary tumors, limited nodal burden, good performance status, and metachronous presentation. These patient and tumor attributes have consistently been demonstrated to predict for OS and PFS in patients with oligometastatic NSCLC.

Unfortunately, there is little consistency in the treatment paradigms and therapeutic options for these patients. Once again, patient selection is critical in determining the best treatment approach. Although systemic therapy has been the historical standard treatment, it continues to maintain a vital role, given the ability to select for patients who may have optimal disease control with first-line agents or those with oligoprogression after first-line chemotherapy, who are then amenable to locally ablative techniques.

In terms of local ablation techniques, surgery alone, RT alone, or a combination of both has been investigated. Given the lack of randomized controlled trials, there are still questions regarding the optimal modality to employ; however, upfront definitive management of lung cancer suffers from the same lack of evidence. Since RT has played a prominent role in the management of stage IV lung cancer, albeit in the palliative setting, many studies have used this approach in the oligometastatic setting. Optimal radiation approaches include SBRT for small metastatic lesions in noncritical locations and hypofractionated RT for tumors in eloquent locations and/or larger size. Studies using these techniques have demonstrated benefit in terms of local control and PFS. Toxicity is minimal given the noninvasiveness and avoidance of critical organs at risk.

Surgery also appears to be safe in this population; however, consideration needs to be given to whether the patient is medically and anatomically operable and the toxicity of surgical resection. Surgical excision is usually reserved for medically operable patients with solitary oligometastasis in a favorable location or in patients with operable solitary intracranial disease, usually followed by radiation. Aggressive neoadjuvant chemotherapy followed by surgery can be very toxic, and the ability to tolerate both is often limited.

Although our understanding of oligometastatic NSCLC has progressed significantly over the recent decades, there is much more to learn and discover. Optimal patient selection remains an important topic to research as is the optimal treatment approach. The understanding that NSCLC is not a single disease entity, but a heterogeneous cluster of histological subtypes with variable disease behaviors and prognoses have contributed significantly to patient selection and identification of the oligometastatic state. The molecular analyses of NSCLC tumor cells and subsequent development of targetable mutations are very active areas of research and will continue to identify subsets of NSCLC with longer disease-free intervals that may benefit from aggressive treatment of oligoprogressive metastases. The hope is that, with each new study on oligometastatic NSCLC, we will be able to improve patient outcomes and confidently conclude that this disease entity exists and, yes, it can be cured.

\section{Disclosure}

The authors report no conflicts of interest in this work.

\section{References}

1. Siegel RL, Miller KD, Jemal A. Cancer statistics, 2015. CA Cancer J Clin. 2015;65(1):5-29.

2. Chen VW, Ruiz BA, Hsieh MC, Wu XC, Ries LA, Lewis DR. Analysis of stage and clinical/prognostic factors for lung cancer from SEER registries: AJCC staging and collaborative stage data collection system. Cancer. 2014;120(suppl 23):3781-3792.

3. Grossi F, Kubota K, Cappuzzo F, et al. Future scenarios for the treatment of advanced non-small cell lung cancer: focus on taxane-containing regimens. Oncologist. 2010;15(10):1102-1112.

4. Hellman S, Weichselbaum RR. Oligometastases. J Clin Oncol. 1995; 13(1):8-10.

5. Vogelstein B, Kinzler KW. The multistep nature of cancer. Trends Genet. 1993;9(4):138-141.

6. Tomlinson JS, Jarnagin WR, DeMatteo RP, et al. Actual 10-year survival after resection of colorectal liver metastases defines cure. J Clin Oncol. 2007;25(29):4575-4580.

7. Simmonds PC, Primrose JN, Colquitt JL, Garden OJ, Poston GJ, Rees M. Surgical resection of hepatic metastases from colorectal cancer: a systematic review of published studies. Br J Cancer. 2006;94(7):982-999.

8. Ferlito A, Shaha AR, Silver CE, Rinaldo A, Mondin V. Incidence and sites of distant metastases from head and neck cancer. ORL J Otorhinolaryngol Relat Spec. 2001;63(4):202-207.

9. Berman AT, Thukral AD, Hwang WT, Solin LJ, Vapiwala N. Incidence and patterns of distant metastases for patients with early-stage breast cancer after breast conservation treatment. Clin Breast Cancer. 2013;13(2):88-94.

10. Billingsley KG, Burt ME, Jara E, et al. Pulmonary metastases from soft tissue sarcoma: analysis of patterns of diseases and postmetastasis survival. Ann Surg. 1999;229(5):602-610. discussion 610-602. 
11. Mitry E, Guiu B, Cosconea S, Jooste V, Faivre J, Bouvier AM. Epidemiology, management and prognosis of colorectal cancer with lung metastases: a 30-year population-based study. Gut. 2010;59(10):1383-1388.

12. Pastorino U, Buyse M, Friedel G, et al; International Registry of Lung Metastases. Long-term results of lung metastasectomy: prognostic analyses based on 5206 cases. JThorac Cardiovasc Surg. 1997;113(1):37-49.

13. Ashworth A, Rodrigues G, Boldt G, Palma D. Is there an oligometastatic state in non-small cell lung cancer? A systematic review of the literature. Lung Cancer. 2013;82(2):197-203.

14. Ashworth AB, Senan S, Palma DA, et al. An individual patient data metaanalysis of outcomes and prognostic factors after treatment of oligometastatic non-small-cell lung cancer. Clin Lung Cancer. 2014;15(5):346-355.

15. Tanvetyanon T, Robinson LA, Schell MJ, et al. Outcomes of adrenalectomy for isolated synchronous versus metachronous adrenal metastases in non-small-cell lung cancer: a systematic review and pooled analysis. J Clin Oncol. 2008;26(7):1142-1147.

16. Schuette W. Treatment of brain metastases from lung cancer: chemotherapy. Lung Cancer. 2004;45(supp1 2):S253-S257.

17. Gaspar L, Scott C, Rotman M, et al. Recursive partitioning analysis (RPA) of prognostic factors in three radiation therapy oncology group (RTOG) brain metastases trials. Int J Radiat Oncol Biol Phys. 1997;37(4):745-751.

18. Patchell RA, Tibbs PA, Walsh JW, et al. A randomized trial of surgery in the treatment of single metastases to the brain. $N$ Engl J Med. 1990;322(8):494-500.

19. Patchell RA, Tibbs PA, Regine WF, et al. Postoperative radiotherapy in the treatment of single metastases to the brain: a randomized trial. JAMA. 1998;280(17):1485-1489.

20. Alexander E 3rd, Moriarty TM, Davis RB, et al. Stereotactic radiosurgery for the definitive, noninvasive treatment of brain metastases. J Natl Cancer Inst. 1995;87(1):34-40.

21. Kondziolka D, Patel A, Lunsford LD, Kassam A, Flickinger JC. Stereotactic radiosurgery plus whole brain radiotherapy versus radiotherapy alone for patients with multiple brain metastases. Int $J$ Radiat Oncol Biol Phys. 1999;45(2):427-434.

22. Aoyama H, Shirato H, Tago M, et al. Stereotactic radiosurgery plus whole-brain radiation therapy vs stereotactic radiosurgery alone for treatment of brain metastases: a randomized controlled trial. JAMA. 2006;295(21):2483-2491.

23. Andrews DW, Scott CB, Sperduto PW, et al. Whole brain radiation therapy with or without stereotactic radiosurgery boost for patients with one to three brain metastases: phase III results of the RTOG 9508 randomised trial. Lancet. 2004;363(9422):1665-1672.

24. Kocher M, Soffietti R, Abacioglu U, et al. Adjuvant whole-brain radiotherapy versus observation after radiosurgery or surgical resection of one to three cerebral metastases: results of the EORTC 22952-26001 study. J Clin Oncol. 2011;29(2):134-141.

25. Cortes J, Rodriguez J, Aramendia JM, et al. Front-line paclitaxel/ cisplatin-based chemotherapy in brain metastases from non-small-cell lung cancer. Oncology. 2003;64(1):28-35.

26. Franciosi V, Cocconi G, Michiara M, et al. Front-line chemotherapy with cisplatin and etoposide for patients with brain metastases from breast carcinoma, nonsmall cell lung carcinoma, or malignant melanoma: a prospective study. Cancer. 1999;85(7):1599-1605.

27. Wroński M, Arbit E, Burt M, Galicich JH. Survival after surgical treatment of brain metastases from lung cancer: a follow-up study of 231 patients treated between 1976 and 1991. J Neurosurg. 1995;83(4):605-616.

28. Bonnette P, Puyo P, Gabriel C, et al; Groupe Thorax. Surgical management of non-small cell lung cancer with synchronous brain metastases Chest. 2001;119(5):1469-1475.

29. Burt M, Wronski M, Arbit E, Galicich JH. Resection of brain metastases from non-small-cell lung carcinoma. Results of therapy. Memorial Sloan-Kettering Cancer Center Thoracic Surgical Staff. J Thorac Cardiovasc Surg. 1992;103(3):399-410. discussion 410-391.

30. Torre M, Barbieri B, Bera E, Locicero S, Pieri Nerli F, Belloni PA. Surgical therapy in lung cancer with single brain metastasis. Eur $J$ Cardiothorac Surg. 1988;2(5):336-339.
31. Harpole D, Amos A, Alexander E, et al. Stage of the primary is important when treating isolated brain metastases from lung cancer. Paper presented at: American Society of Clinical Oncology Annual Meeting; 1996; Philadelphia, PA.

32. van Meerbeeck JP, Kramer GW, Van Schil PE, et al; European Organisation for Research and Treatment of Cancer-Lung Cancer Group. Randomized controlled trial of resection versus radiotherapy after induction chemotherapy in stage IIIA-N2 non-small-cell lung cancer. J Natl Cancer Inst. 2007;99(6):442-450.

33. Albain KS, Swann RS, Rusch VW, et al. Radiotherapy plus chemotherapy with or without surgical resection for stage III non-small-cell lung cancer: a phase III randomised controlled trial. Lancet. 2009;374(9687):379-386.

34. Hu C, Chang EL, Hassenbusch SJ 3rd, et al. Nonsmall cell lung cancer presenting with synchronous solitary brain metastasis. Cancer. 2006;106(9):1998-2004.

35. Arrieta O, Villarreal-Garza C, Zamora J, et al. Long-term survival in patients with non-small cell lung cancer and synchronous brain metastasis treated with whole-brain radiotherapy and thoracic chemoradiation. Radiat Oncol. 2011;6:166.

36. Rusthoven KE, Hammerman SF, Kavanagh BD, Birtwhistle MJ, Stares M, Camidge DR. Is there a role for consolidative stereotactic body radiation therapy following first-line systemic therapy for metastatic lung cancer? A patterns-of-failure analysis. Acta Oncol. 2009;48(4):578-583.

37. Mehta N, Mauer AM, Hellman S, et al. Analysis of further disease progression in metastatic non-small cell lung cancer: implications for locoregional treatment. Int J Oncol. 2004;25(6):1677-1683.

38. Xanthopoulos E, Handorf E, Simone C, et al. Definitive dose thoracic radiation therapy in oligometastatic non-small cell lung cancer: a hypothesis-generating study. Pract Radiat Oncol. 2015;5(4):e355-e363.

39. Timmerman R, Paulus R, Galvin J, et al. Stereotactic body radiation therapy for inoperable early stage lung cancer. JAMA. 2010;303(11):1070-1076.

40. Kelsey CR, Salama JK. Stereotactic body radiation therapy for treatment of primary and metastatic pulmonary malignancies. Surg Oncol Clin N Am. 2013;22(3):463-481.

41. Milano MT, Katz AW, Zhang H, Okunieff P. Oligometastases treated with stereotactic body radiotherapy: long-term follow-up of prospective study. Int J Radiat Oncol Biol Phys. 2012;83(3):878-886.

42. Rusthoven KE, Kavanagh BD, Burri SH, et al. Multi-institutional phase I/II trial of stereotactic body radiation therapy for lung metastases. $J$ Clin Oncol. 2009;27(10):1579-1584.

43. Iyengar P, Kavanagh BD, Wardak Z, et al. Phase II trial of stereotactic body radiation therapy combined with erlotinib for patients with limited but progressive metastatic non-small-cell lung cancer. J Clin Oncol. 2014;32(34):3824-3830.

44. Collen C, Christian N, Schallier D, et al. Phase II study of stereotactic body radiotherapy to primary tumor and metastatic locations in oligometastatic nonsmall-cell lung cancer patients. Ann Oncol. 2014;25(10):1954-1959.

45. Palma DA, Haasbeek CJ, Rodrigues GB, et al. Stereotactic ablative radiotherapy for comprehensive treatment of oligometastatic tumors (SABR-COMET): study protocol for a randomized phase II trial. BMC Cancer. 2012;12:305.

46. Beitler AL, Urschel JD, Velagapudi SR, Takita H. Surgical management of adrenal metastases from lung cancer. J Surg Oncol. 1998;69(1):54-57.

47. Luketich JD, Burt ME. Does resection of adrenal metastases from non-small cell lung cancer improve survival? Ann Thorac Surg. 1996;62(6):1614-1616.

48. Porte H, Siat J, Guibert B, et al. Resection of adrenal metastases from non-small cell lung cancer: a multicenter study. Ann Thorac Surg. 2001;71(3):981-985.

49. Downey RJ, Ng KK, Kris MG, et al. A phase II trial of chemotherapy and surgery for non-small cell lung cancer patients with a synchronous solitary metastasis. Lung Cancer. 2002;38(2):193-197.

50. De Ruysscher D, Wanders R, van Baardwijk A, et al. Radical treatment of non-small-cell lung cancer patients with synchronous oligometastases: long-term results of a prospective phase II trial (Nct01282450). $J$ Thorac Oncol. 2012;7(10):1547-1555. 
51. Yano T, Okamoto T, Haro A, et al. Local treatment of oligometastatic recurrence in patients with resected non-small cell lung cancer. Lung Cancer. 2013;82(3):431-435.

52. Solomon BJ, Mok T, Kim DW, et al; PROFILE 1014 Investigators. First-line crizotinib versus chemotherapy in ALK-positive lung cancer. N Engl J Med. 2014;371(23):2167-2177.

53. Rosell R, Carcereny E, Gervais R, et al; Spanish Lung Cancer Group in collaboration with Groupe Français de Pneumo-Cancérologie and Associazione Italiana Oncologia Toracica. Erlotinib versus standard chemotherapy as first-line treatment for European patients with advanced EGFR mutation-positive non-small-cell lung cancer (EURTAC): a multicentre, open-label, randomised phase 3 trial. Lancet Oncol. 2012;13(3):239-246.

54. Doebele RC, Pilling AB, Aisner DL, et al. Mechanisms of resistance to crizotinib in patients with ALK gene rearranged non-small cell lung cancer. Clin Cancer Res. 2012;18(5):1472-1482.

55. Camidge DR, Bang YJ, Kwak EL, et al. Activity and safety of crizotinib in patients with ALK-positive non-small-cell lung cancer: updated results from a phase 1 study. Lancet Oncol. 2012;13(10): 1011-1019.

56. Gan GN, Weickhardt AJ, Scheier B, et al. Stereotactic radiation therapy can safely and durably control sites of extra-central nervous system oligoprogressive disease in anaplastic lymphoma kinase-positive lung cancer patients receiving crizotinib. Int J Radiat Oncol Biol Phys. 2014;88(4):892-898.

57. Yu HA, Sima CS, Huang J, et al. Local therapy with continued EGFR tyrosine kinase inhibitor therapy as a treatment strategy in EGFRmutant advanced lung cancers that have developed acquired resistance to EGFR tyrosine kinase inhibitors. J Thorac Oncol. 2013;8(3): $346-351$.
58. Moazami N, Rice T, Rybicki L, et al. Stage III non-small cell lung cancer and metachronous brain metastases. J Thorac Cardiovasc Surg. 2002;124(1):113-122.

59. Abrahams J, Torchia M, Putt M, et al. Risk factors affecting survival after brain metastases from non-small cell lung carcinoma: a follow-up study of 70 patients. J Neurosurg. 2001;95(4):595-600.

60. Flannery T, Suntharalingam M, Regine W, et al. Long-term survival in patients with synchronous, solitary brain metastasis from non-small-cell lung cancer treated with radiosurgery. Int J Radiat Oncol Biol Phys. 2008;72(1):19-23.

61. Parikh R, Cronin A, Kozono D, et al. Definitive primary therapy in patients presenting with oligometastatic non-small cell lung cancer. Int J Radiat Oncol Biol Phys. 2014;89(4):880-887.

62. Lopez Guerra J, Gomez D, Zhuang Y, et al. Prognostic impact of radiation therapy to the primary tumor in patients with non-small cell lung cancer and oligometastasis at diagnosis. Int J Radiat Oncol Biol Phys. 2012;84(1):e61-67

63. Hasselle M, Haraf D, Rusthoven K, et al. Hypofractionated imageguided radiation therapy for patients with limited volume metastatic non-small cell lung cancer. J Thorac Oncol. 2012;7(2):376-381.

64. Collaud S, Stahel R, Inci I, et al. Survival of patients treated surgically for synchronous single-organ metastatic NSCLC and advanced pathologic TN stage. Lung Cancer. 2012;78(3):234-238

65. Voltolini L, rapicetta C, Luzzi L, et al. Surgical treatment of synchronous multiple lung cancer located in a different lobe or lung: high survival in node-negative subgroup. Eur $J$ Cardiothorac Surg. 2010;37(5):1198-1204.

66. Hanagiri T, Takenaka M, Oka S, et al. Results of a surgical resection for patients with stage IV non--small-cell lung cancer. Clin Lung Cancer. 2012;13(3):220-224.
Lung Cancer: Targets and Therapy

\section{Publish your work in this journal}

Lung Cancer: Targets and Therapy is an international, peer-reviewed, open access journal focusing on lung cancer research, identification of therapeutic targets and the optimal use of preventative and integrated treatment interventions to achieve improved outcomes, enhanced survival and quality of life for the cancer patient. Specific topics covered in the journal include: Epidemiology, detection and screening; Cellular research and biomarkers; Identification of biotargets and agents with novel

Submit your manuscript here: https://www.dovepress.com/lung-cancer-targets--therapy-journal

\section{Dovepress}

mechanisms of action; Optimal clinical use of existing anticancer agents, including combination therapies; Radiation and surgery; Palliative care; Patient adherence, quality of life, satisfaction; Health economic evaluations. The manuscript management system is completely online and includes a very quick and fair peer-review system. Visit http://www.dovepress.com/testimonials.php to read real quotes from published authors. 